\title{
La necesidad de la teoría en el espacio académico de reflexión sobre las artes.
}

Dr. Arturo Valencia Ramos

Correo: arturo@capomo.uson.mx

Universidad de Sonora

Departamento de Bellas Artes

Recibido para su publicación: 30 de agosto de 2015

Aprobado: 01 de octubre de 2015

\section{A manera de introducción}

Escribo este artículo como una reflexión y teniendo en mente a los estudiantes de artes de la Universidad de Sonora. Es con ellos con quienes convivo y hacia quienes oriento mi práctica docente. Si lo que aquí escribo es observable en espacios académicos de otras instituciones de educación superior, como parece que así es al menos en la realidad mexicana, no es producto de algo fortuito sino más bien la corroboración del problema que en esta ocasión estoy abordando.

\section{¿Es necesario estudiar teoría?}

Desde hace ya tiempo en el espacio social de los estudiantes de arte circulan los presupuestos que fundamentan los estudios de estética. Ya Adolfo Sánchez Vázquez (1992) en su texto por demás didáctico ha justificado la existencia misma de la disciplina así como las diversas formas de su abordaje; sin embargo parece que la recurrencia de su cuestionamiento surge a cada momento como una suerte de fantasma que nos obliga constantemente a responder sobre su necesidad en los estudios universitarios.

El origen de la discusión radica en que no siempre al estudiante le queda clara esa necesidad cuando su motivación al ingresar a una escuela o facultad de arte es, justamente, convertirse en artista al final de su trayectoria escolar. No tiene una distinción precisa de los requerimientos que conlleva esa trayectoria frente a la libertad que siente perder como creador o ejecutante.

Al observar a su entorno se encuentra con un medio en el cual el aprendizaje autodidacta parece rendir mejores frutos que el esfuerzo invertido durante cuatro años, como mínimo, en las aulas donde cuestiona toda posibilidad de avance. La intensidad del cuestionamiento se presenta en relación directa al aumento de su prisa por egresar y más de un caso en algún punto de la trayectoria se desenvuelve como profesional sea en los escenarios o en las salas de exposiciones. Así que el estudio académico parece convertirse cada vez más en un apéndice necesario el cual debe sufrir para al final convertirse en artista.

Lo que pasa por alto es que a todo estudiante de cualquier profesión le sucede lo mismo: también ese estudiante tiene prisa y también cuestiona, de tal forma que lo que considera necesario aprender son las herramientas y las técnicas para desenvolverse con eficiencia en el mercado laboral. Si ya de suyo el estudiante toma el espacio académico para socializar, la teoría se ve desplazada al punto más lejano de sus intereses y cuando se ve forzado a abordarla lo hace para obtener una calificación aprobatoria en el examen.

En el caso específico de los estudiantes de artes las preguntas son: ¿Es necesario estudiar teoría del arte? ¿Es necesario estudiar estética? Una respuesta pragmática nos conduce a la selección: sí, cuando nos desenvolvemos en el espacio académico; no, cuando estamos fuera de él. A partir de esa selección comienzan a operar los mecanismos de inclusión y exclusión en los espacios sociales de producción de conocimiento y discurso. He ahí la contingencia. Dado que nosotros hemos seleccionado el espacio académico vemos no solo necesario el estudio de la teoría del arte y la estética, sino lo asumimos como el fundamento de toda actividad ulterior. El propósito de este artículo es argumentar esa necesidad, y para ello vamos a partir desde un principio de "que la teoría es una construcción intelectual que aparece como resultado del trabajo filosófico o científico" (Ferrater Mora, 1964, p. 776).

\section{El arte en el entorno de la producción cultural}

Aunque este no es el espacio para definir qué es la cultura sí podemos argumentar cuál es el lugar que ocupa el arte frente a ella. Hasta ahora la noción más socorrida de cultura la constituye como un todo que permea a la sociedad $y$, a pesar de todas las discusiones acerca de su definición 
(Goberna Falque, 2003), de alguna manera la define. Sin embargo, si entendemos al arte como un sistema, la cultura constituiría parte del entorno y ella misma se convertiría en una perspectiva para la observación (Cf. Luhmann, 1997). Concebir así las cosas es ya de suyo un acto de teorizar y por sí mismo justifica su estudio. He ahí el primer argumento y, probablemente, el basamento desde el cual desplegar toda otra teoría. El entramado de significaciones de la cultura (Cf. Geertz, 1983) pasaría entonces al terreno de la comunicación.

Como se puede observar, esto implica un giro al desplazar la idea del arte como formando parte de las manifestaciones culturales de la sociedad para ubicar la discusión en la noción de la diferencia sistema/entorno. Si esto es así deberíamos revisar las contribuciones ontológicas a las reflexiones sobre el arte y proponer nuevos modelos para su descripción e interpretación. Desde mi punto de vista, y siempre siguiendo a Luhmann (2005), no se trata de hacer una nueva interpretación sociológica, filosófica, antropológica, etcétera (que en principio terminan concibiendo al arte como objeto) sino ubicar las zonas de interpenetración y acoplamiento estructural del arte frente a lo que constituye su entorno. Solo con ello se lograría la autonomía del arte no únicamente en sus procesos de producción, sino en los abordajes de la teoría. He aquí un segundo argumento.

\section{Las ideas estéticas}

El arte, ontologizado desde los orígenes de

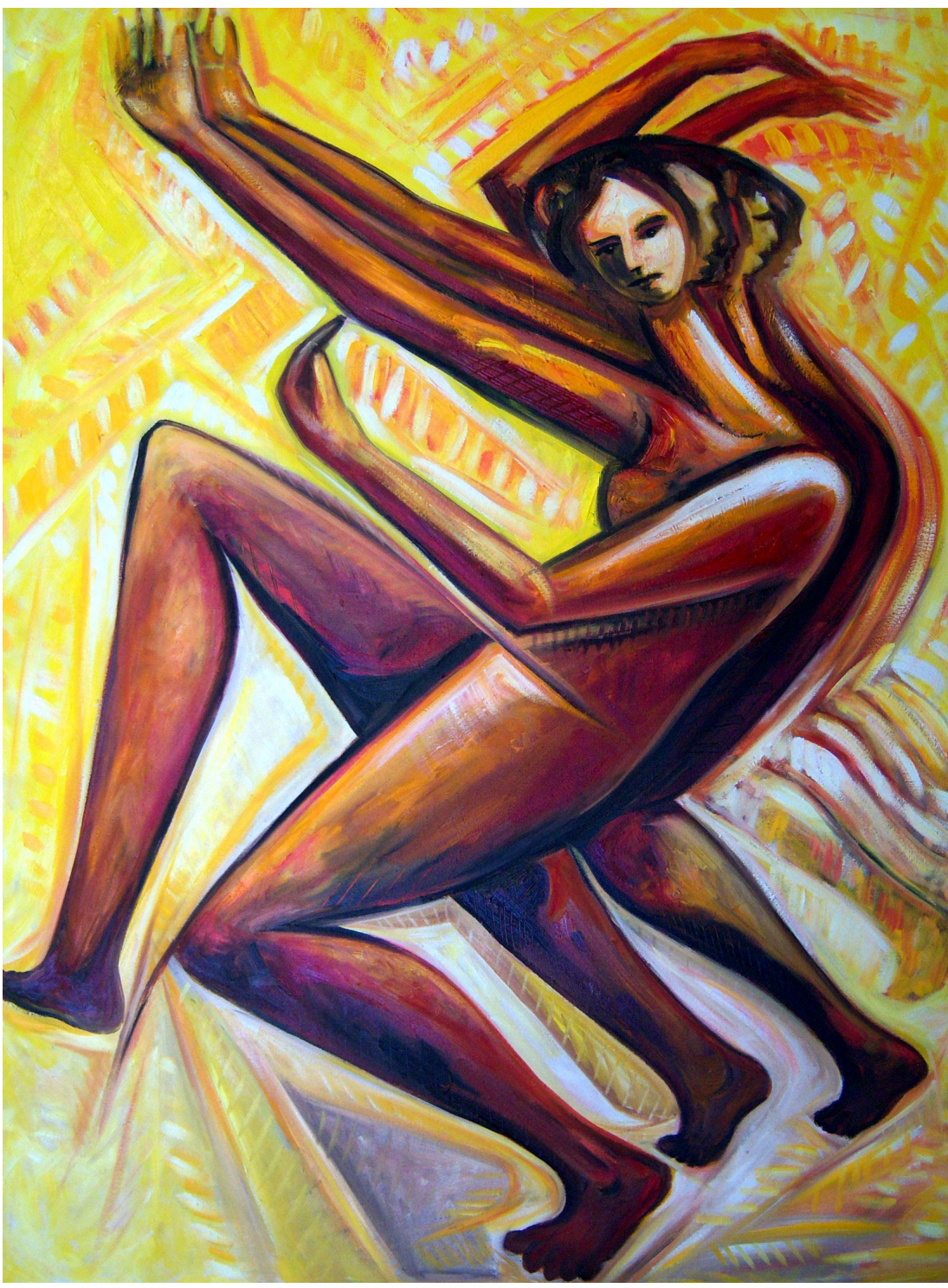

Autor:Gustavo Ozuna

Titulo: Danzantez

Tecnica: Oleo la tradición filosófica, es un objeto para la reflexión estética que Alexander Baumgarten concibe como la "ciencia del conocimiento sensible o gnoseología inferior" (Citado en Herrero Estrada, 1988, p. 23), porque "la lógica, o gnoseología superior [...] tiene en el conocimiento intelectual su propio campo"(1988, p. 24). A partir de esa concepción el "objeto estético" es obra de arte y obra de la naturaleza, con la particularidad que nos afecta de manera distinta a otras "entidades del mundo circundante"(1988, p. 39). Es decir, la obra de arte en su calidad de ente, es un objeto a estudiar desde el horizonte de observación de la filosofía, pero no en el terreno de la razón, sino en el espacio de lo sensible. 
Hemos citado a Baumgarten porque es el iniciador de una discusión sobre el arte desde una perspectiva científica, pero el lector sabe que tanto antes como después de él, el arte ya ha sido objeto de reflexión. La bibliografía al respecto es larga así como la nómina de quienes lo han abordado. Sin embargo, a partir de sus contribuciones el arte es objeto de una ciencia y esa ciencia es la estética.

De igual forma la historia de las ideas estéticas nos han permitido observar la evolución misma de la historia del arte (y viceversa) así como las concepciones que le han corrido aparejadas y no podemos ser anacrónicos al respecto: las teorías han sido correspondientes al período de sus formulaciones y han respondido a los presupuestos de sus respectivas actualidades.

A partir de esa construcción intelectual que llamamos teoría es que la tradición occidental ha construido también las diferentes ideas que sobre el arte se han presentado a lo largo de la historia. El texto elemental de Raymond Bayer (2011) y con el cual trabajamos muchos profesores de estética y teoría del arte propone desde las primeras líneas del prefacio a la estética como una "reflexión acerca del arte" y es justo a lo que se dedica a lo largo del libro. Sin embargo la conclusión puede contravenir otras disposiciones teóricas contemporáneas al texto y posteriores a él e, incluso, es perceptible en ella una orientación formalista: "La obra de arte, que constituye uno de los objetos de estudio de la estética es todo lo opuesto de un hecho histórico. No solamente el arte no se desarrolla forzosamente al compás de la historia, sino que además no es el reflejo de los acontecimientos históricos y políticos." (Bayer, 2011, p. 449).

Este tipo de afirmaciones, resulta obvio decirlo, es consustancial al horizonte de observación y al posicionamiento teórico de quien la emite; pero no solo eso: también demuestra la insostenibilidad del posicionamiento aún desde la reflexión filosófica-sin decir la histórica o la sociológica. De ahí la necesidad de la teoría y, si somos extensivos, podemos decir el requerimiento de teorías que estén en relación directa con las ideas que permitan operacionalizar su descripción y análisis. Los volúmenes que Valeriano Bozal (2000) ha editado sobre las ideas estéticas contem- poráneas nos permiten abrir el abanico de la reflexión y contrastar los diferentes posicionamientos y complementan con mucho las reflexiones propuestas por Bayer.

\section{La estética y el artista}

El conflicto que tienen los estudiantes de arte y los artistas es que aparentemente los estudios de estética poco abonan para la buena ejecución de su obra. Así lo propone Sánchez Vázquez después de presentar lo que el artista diría en relación al tema:

El artista, en verdad, no es por principio un teórico, pero un poco de teoría-cuando ésta hunde sus raíces en la práctica-no le sobra. A veces, insatisfecho e impaciente con lo que los teóricos le dicen, se pregunta inquieto por qué han de ser ellos y no élque cuenta con el rico e insustituible bagaje de su experiencia creadora-quien reflexione sobre ella. (Sánchez Vázquez, 1992, p. 40).

Esto contrasta con muchos artistas que han reflexionado sobre su práctica, que han teorizado sobre ella y a partir de ella han fijado la producción de sus obras. El asunto es que sus reflexiones (salvo casos excepcionales) no se han ubicado en el mismo nivel que las reflexiones de filósofos, sociólogos o historiadores del arte. Esto hace aparente que casi siempre las reflexiones sobre el arte no provengan de los propios artistas, a pesar de que son ellos quienes producen los "objetos" que aquéllos estudian. Sin embargo si, en principio, giramos del objeto al discurso encontramos que "el arte mismo es 'discurso' - un campo conceptual dentro y alrededor del cual se mueven varios tipos de objetos, actividades, procesos, ideas y teorías, subculturas y movimientos, instituciones y exposiciones." (Costello, Diarmuid y Vickery, 2007, p. 10).

Si aceptamos esta afirmación podemos observar que se requieren replanteamientos teóricos que permitan el abordaje del arte y, aún más, el abordaje de sus producciones. Esto nos llevaría a abrir más el abanico para situarnos en la pluralidad de esas producciones. La estética, entonces dejaría de tomarse como una teoría general y podemos aventurar la confección de estéticas particulares relacio- 
nadas con prácticas particulares. El artista, de este modo, estaría en las mismas condiciones para aportar al conocimiento del arte y a no ver relegado su pensamiento a la sola ejecución de su práctica. Es necesario entonces, como señala Luhmann, ir de una teoría representacional a una constructivista y que la teoría del arte se coloque sobre bases radicalmente distintas (2005, p. 20). Así, lo que Costello entiende como "discurso" yo lo propondría como sistema, lo cual implica un cambio paradigmático en la perspectiva de descripción y análisis.

Es necesario ubicar la teoría en su temporalidad, que Ernst Gombrich (2002) propuso como una forma de resolver la comprensión de la expresividad en diferentes períodos de la historia. Al final de su conferencia el ejemplo resulta muy ilustrativo:

Con el fin de ilustrar todas estas ideas, y a modo de resumen, me gustaría poner un ejemplo del lenguaje de la música; en concreto, el de un simple toque de trompeta. En la antigüedad clásica se hubiera puesto el acento en la capacidad de este instrumento para suscitar el valor y la agresividad. En la época del renacimiento y barroco se hubiera utilizado por ejemplo, en una ópera - para representar el espíritu marcial. Un compositor romántico es posible que insertara un toque de trompeta en su sinfonía para expresar la emoción del triunfo.

Si el arte y su práctica han evolucionado, ¿por qué no habría de hacerlo la teoría? No estoy proponiendo aquí, aunque me gustaría, elaborar una teoría nueva del arte, sino replantear las teorías que ya conocemos y hacerlas comprensibles al estudiante de arte de tal manera que, una vez transformado en artista, pueda consumirlas no como una medicina amarga sino como algo propio de su actividad. Esto nos conduce a otro punto en la discusión.

\section{¿Para qué investigar?}

Hoy en día, a pesar de las discusiones y posiciones encontradas, resulta un paradigma regresivo profundizar las diferencias entre el arte y la ciencia y, sobre todo, canonizar la sobrevaloración que se hace de la teoría científica versus la teoría del arte. En el reciente congreso Palas y las $\mathrm{Mu}$ sas: Diálogos entre la ciencia y el arte, organizado por el Instituto de Investigaciones Estéticas y por el Instituto de
Investigaciones en Matemáticas Aplicadas y en Sistemas de la UNAM, en la ciudad de Guanajuato durante agosto de 2014, quedaron expuestas de manera clara y concisa las relaciones de colaboración entre estos dos grandes espacios de la actividad humana.

Parto, en este punto de la argumentación, de la convicción de que el arte además de producir emociones produce también conocimiento y retomo aquí lo expresado por Óscar Cornago:

Los métodos en ciencias serían comparables a los géneros en arte, y si hace tiempo que el artista tiene que ser a su vez creador de las propias reglas del juego sobre las que va a construir la obra, en un momento en que los géneros ya no valen para legitimar un tipo u otro de práctica, con más razón se habrán de construir igualmente los canales que transformen su hacer en forma de conocimiento.(Cornago, 2010, p. 19).

Observamos de esta manera que investigar ha sido siempre una actividad consustancial a la práctica artística. Ya otros autores, tanto artistas como académicos han abundado en la cuestión, así como sus problemáticas en los espacios universitarios (Cf. Borgdorff, s. f.; Fajardo-González, s. f.). Párrafos arriba en este artículo he señalado la necesidad de estudiar estética y, por extensión, señalo también la necesidad de la investigación y la teoría. Y es que esos son los espacios idóneos para la reflexión; de hecho, esa es su razón de ser.

En las escuelas y facultades de literatura nadie discute la pertinencia de estudiar teoría literaria o estilísticaasí existan diferencias o posiciones encontradas respecto a tal o cual teoría. Pero parece que la literatura se desagrega de las artes y su estudio se nos presenta como especializado. En el espacio de la literatura es práctica común discutir la teoría en relación a creadores literarios, muchos de los cuales también ejercen la docencia, la reflexión y la crítica. Uno de los argumentos para que tal cosa suceda así, es que los estudiantes y los profesionales de literatura tienen como práctica común leer y escribir y, por tanto, se encuentran más cerca de la reflexión y la teoría. En cambio-continúa la argumentación-los estudiantes de artes visuales, plásticas, artes escénicas o música no tienen como práctica habitual la lectura en la ejecución de alguna de sus artes...y 
por eso no requieren teorizar. Este argumento, además de nimio resulta incongruente en los espacios académico así que por principio debe rechazarse.

Lo que se requiere, en todo caso, es operacionalizar la teoría y construir modelos para la descripción y el análisis, sea que la investigación sirva para crear obra, o bien que se conduzca para la generación de conocimiento. Desde mi punto de vista, sin embargo, esta aparente dualidad queda resuelta en algún punto de diferenciación creciente. Nuestra tarea consiste, entonces, como profesores, como investigadores y como artistas, en establecer ese punto de la diferenciación.

\section{A manera de conclusión}

Retomando a Sánchez Vázquez nos podemos preguntar de nuevo: ¿Por qué son otros y no los artistas los que teorizan sobre el arte? Una respuesta inmediata nos conduce a indagar como profesores de arte sobre nuestra práctica docente y en un ejercicio de autocrítica, sin que esto signifique rasgarnos las vestiduras, evaluar nuestra propia disposición a la teoría y nuestra apertura a otros paradigmas. Esa respuesta de alguna manera nos conducirá a la generación de modelos propios para abordar el arte, sus actores, procesos, productos y, sobre todo, de manera recursiva a la observación de nuestra práctica.

\section{Bibliografía}

Bayer, R. (2011). Historia de la Estética. México: Fondo de Cultura Económica.

Borgdorff, H. (s. f.). El debate sobre la investigación en las artes. Recuperado 3 de octubre de 2015, a partir de http://webcache.googleusercontent.com/search?q=cache:vH4DddAmNOsJ:www.gu.se/digitalAssets/1322/1322698_el-debate-sobre-la-investigaci--n-en-las-artes.doc+\&cd=9\&hl=es\&ct=clnk\&gl=mx

Bozal, Valeriano (Ed.). (2000). Historia de las Ideas Esteticas Vol I. Visor.

Clifford Geertz. La interpretación de las culturas. | Nueva Revista. (s. f.). Recuperado 1 de octubre de 2015, a partir de http://www.nuevarevista.net/articulos/clifford-geertz-la-interpretacion-de-las-culturas

Cornago, Ó. (2010, diciembre). Artes y Humanidades: una cuestión de formas (de hacer). Telondefondo. Revista de teoría y crítica teatral. No. 12. Recuperado a partir de www.telondefondo.org

Costello, Diarmuid y Vickery, J. (2007). Art: Key contemporary thinkers. Oxford: Berg.

Fajardo-González, R. (s. f.). La investigación en el campo de las Artes Visuales en el ámbito académico universitario. Recuperado a partir de http://webcache.googleusercontent.com/search?q=cache:UYmzkDiEu-IJ:docentes2.uacj.mx/museodigital/cursos_2012/InvestigacionArtesFajardo.pdf+\&cd=4\&hl=es\&ct=clnk\&gl=mx

Ferrater Mora, J. (1964). Diccionario de Filosofía. T.I. Buenos Aires: Editorial Sudamericana.

Geertz, C. (1983). La interpretación de las culturas. Barcelona: Gedisa.

Goberna Falque, J. R. (2003). What's culture? cien años de controversia en la antropología anglosajona (1871-1971). GaIlaecia. Departamento de Historia I: Prehistoria, Arqueoloxía, Historia Antiga, Ciencias e Técnicas Historiográficas e Biblioteconomía e Documentación. Recuperado a partir de http://dialnet.unirioja.es/servlet/articulo?codigo=633501

Gombrich, E. H. (2002). Cuatro teorías sobre la expresión artística. EGA. Revista de Expresión Gráfica Arquitectónica. no7. Recuperado a partir de http://www3.uva.es/ega/wp-content/uploads/teorias-de-la-expresion-ega.pdf

Herrero Estrada, D. (1988). Estética. Barcelona: Herder.

Luhmann, N. (1997). La cultura como concepto histórico. Historia y Grafía. México, D.F.

Luhmann, N. (2005). El Arte de La Sociedad. México: Herder-UIA.

Sánchez Vázquez, A. (1992). Invitación a la estética. México: Editorial Grijalbo. 